\title{
Questão ambiental, reforma agrária e agroecologia: desafios políticos ao MST
}

Mônica Grossi*

\begin{abstract}
Resumo
Delimitamos como objeto de estudo deste artigo a discussão sobre a relação entre questão ambiental, reforma agrária e a construção da agroecologia como estratégia produtiva e política, assumida pelo movimento dos trabalhadores rurais sem terra - MST. Pretendemos analisar, como o MST, através de seu processo de luta, vem construindo a agroecologia como estratégia produtiva e política trazendo contribuições e desafios políticos para a defesa de sua proposição em torno de uma reforma agrária popular.
\end{abstract}

Palavras-chave: Questão ambiental; reforma agrária; agroecologia; MST.

\section{Environmental issues, land reform and agroecology: political challenges to MST}

\begin{abstract}
We have delimited as object of study of this article the discussion on the relationship among environmental issues, land reform and the construction of agroecology as productive and political strategy, assumed by the movement of the landless rural workers - MST. We intend to analyze how MST, through its wrestling process, has been constructing agroecology as a productive and political strategy, bringing contributions and political challenges to defend its proposition around a popular agrarian reform.
\end{abstract}

Keywords: Environmental issues; land reform; agroecology; MST.

Recebido em: 30/11/2017

Aprovado em: 18/12/2017

*Prof. Assistente da FSS/UFJF. Doutora pela ESS/UFRJ; monica.grossi@ hotmail.com 


\section{Introdução}

Este artigo é parte dos estudos desenvolvidos em nossa tese de doutorado, relacionados à análise da politização da questão ambiental no Movimento dos Trabalhadores Rurais Sem Terra - MST. Este processo de reflexão está relacionado à nossa participação nos processos de educação e formação de quadros do MST, desde 2000, e em nosso diálogo com o campo de estudos da geografia agrária.

Delimitamos como objeto de estudo deste artigo a discussão sobre a relação entre questão ambiental, reforma agrária e a construção da agroecologia como estratégia produtiva e política, assumida pelo MST. Pretendemos analisar, como o MST, através de seu processo de luta, vem construindo a agroecologia como estratégia produtiva e política trazendo contribuições e desafios políticos para a defesa de sua proposição em torno de uma reforma agrária popular.

Os procedimentos metodológicos se apóiam na pesquisa bibliográfica e na análise documental, tendo como referencial teórico-metodológico a teoria social marxiana. Os documentos analisados são: cartas dos Congressos Nacionais do MST; documentos do setor de Produção, Cooperação e Meio Ambiente do MST, que orientam e sustentam a construção da agroecologia, nas suas dimensões produtiva e formativa e, a proposta de Reforma Agrária Popular do MST.

\section{Modernização da agricultura capitalista brasileira e a construção da agroecologia}

No período histórico do início do século XX, principalmente no contexto das duas grandes guerras mundiais, temos a ascensão da terceira revolução agrícola, cujas características principais foram: a introdução da mecanização na agricultura de grande escala, substituindo a tração animal; a criação de animais de maneira concentrada em grandes estábulos e a introdução da química, através da alteração genética de plantas e do uso intensivo de fertilizantes e pesticidas sintéticos.

A realização das duas guerras mundiais foi determinante para a difusão deste padrão capitalista de agricultura, tendo seu sustentáculo na chamada "revolução verde" que passa a ser adotada em vários países do mundo, especialmente, nos de clima tropical. A revolução verde como estratégia capitalista para a agricultura foi estruturada como forma de aproveitamento dos restos de guerra, pois as indústrias bélicas, símbolo da produção 
destrutiva, e as indústrias químicas, haveriam de se utilizar de sua destruição criativa, em relação às sobras de produtos que poderiam ser empregados em outro ramo de atividade lucrativo, como de fato ocorreu na agricultura. Assim, houve o aproveitamento de produtos, como tanques de guerra e gases mortais, que se transformaram em máquinas e venenos (agrotóxicos) a serem utilizados na sustentação da agricultura capitalista monocultora de grande escala, através do pacote tecnológico da revolução verde, que fariam uma verdadeira operação de guerra no campo para cumprir o objetivo nobre e declarado de acabar com a fome. E obviamente, trariam ganhos extraordinários aos seus investidores capitalistas, tanto do ramo industrial como do ramo agrícola.

A criação de condições artificiais visando ao aumento da produtividade na produção agrícola, para atingir o objetivo de acabar com a fome revela a falácia da revolução verde, adotada pelo Brasil a partir de 1964, pela ditadura militar, como elemento central de seu processo de modernização conservadora. Encontrou forte apoio de setores agrários conservadores e de empresas, com interesses amplamente voltados para investimentos no ramo agroquímico e de motomecanização.

Delgado(2010) destaca, na modernização conservadora do regime militar(1964-1982), o papel da agricultura na economia brasileira, que passa a incorporar um elemento novo em relação ao período anterior, que se refere ao aprofundamento das relações técnicas da agricultura com a indústria e de ambos com o setor externo, com a subvenção da política agrícola e comercial do período.Segundo este autor, o processo de modernização técnica e de junção com a indústria

[...] é caracterizado, por um lado, pela mudança na base técnica de meios de produção utilizados pela indústria, materializadas na presença crescente de insumos industriais(fertilizantes, defensivos, corretivos do solo, sementes melhoradas e combustíveis líquidos); e máquinas industriais(tratores,colhedeiras, equipamentos de irrigação e outros implementos). Por outro, ocorre uma integração de grau variável entre a produção primária de alimentos e matérias-primas e vários ramos industriais, como oleaginosos, moinhos, indústrias de cana e papelão, fumo, têxtil e bebidas. Estes blocos irão constituir mais adiante a chamada estratégia do agronegócio, que vem crescentemente dominando a política agrícola no Estado (p.86).

A defesa do progresso tecnológico e da contínua inovação para a superação dos limites naturais, que se estabeleceram como barreiras, foi base fundante do desenvolvimento da agricultura industrial. No entanto, em que pese todo investimento industrial para controlar estes fatores naturais, a produção da agricultura não pode se desligar dos ciclos e reações da natureza. E desde então, e até hoje, são estes limites que desmentem esta crença no progresso infindável da tecnologia, uma vez que a agricultura capitalista passou a se constituir não só 
como grande causadora dos problemas ambientais, mas também como o setor mais afetado negativamente por esta perspectiva de desenvolvimento.

Motta e Mendonça (in MOTTA, 2005) ao analisarem a penetração do capitalismo no campo brasileiro, sobretudo a partir da década de 1970, quando se fortalece a fusão entre agricultura e indústria, dando origem aos Complexos Agroindustriais - CAIs - representantes do moderno padrão de agricultura, destacam a afirmação de dois padrões de produção rural, o capitalista e o da agricultura familiar. E por esta visão hegemônica do capitalismo, a realização da reforma agrária é considerada totalmente desnecessária para o tipo de desenvolvimento imposto e "naturalizado" pela modernização da agricultura. O resultado de todo este processo, no final dos anos de 1970, se apresenta através de elementos contraditórios, uma vez que a modernização intensa da agricultura, alcançada com o estímulo e apoio do Estado brasileiro, representaram ao mesmo tempo, um extraordinário avanço tecnológico e do processo de urbanização, e uma elevação exponencial da desigualdade e da queda nas condições de vida no campo. É justamente este contexto que cria as condições para a afirmação do agronegócio, que desenvolve a atividade agrícola, absolutamente articulada e dependente da produção industrial, e também passa a dominar a pesquisa científica, financiando estudos ligados aos interesses das empresas transnacionais.

Mendonça (2006) analisa a relação entre questão agrária e reforma agrária, enfatizando a reflexão política, trazendo elementos fundamentais sobre a formação e conformação das classes dominantes agrárias, como um dos mais importantes frutos da modernização da agricultura brasileira. As redes que se constituem entre as frações do capital - agrário, industrial e financeiro, se complexificam e impõem aos trabalhadores rurais, sob a hegemonia do agronegócio no Brasil, a expulsão, o êxodo rural, a miséria e, por certo, grandes conflitos. E esta situação de conflito no campo demonstra, assim, o questionamento à legitimidade da dominação sobre os trabalhadores.

Sobre a modernização da agricultura brasileira, Alentejano (In: MOTTA, 2005) destaca que a relação entre o agrário e o ambiental deste modelo agrícola produz uma profunda inversão do princípio tradicional que regia a agricultura referente à sua adaptação à diversidade ambiental e sua vinculação a regimes alimentares diversificados. Este modelo ganha sua máxima expressão na atualidade com a dominação feita pelo agronegócio, que sustenta um processo de padronização da agricultura o qual

(...) se impõe à diversidade ambiental, artificializando os ambientes e adequando-os ao padrão mecânico-químico da agricultura moderna, ao mesmo tempo em que 
impõe a todos os povos um padrão alimentar que atende aos interesses das grandes corporações agroindustriais ( p. 478).

Estes elementos fundamentam a critica à agricultura capitalista, sob o domínio do agronegócio, responsável pela desigual e insustentável condição social e ambiental do espaço agrário, que se expressa: no controle e acesso a terra com a manutenção do latifúndio, através da mecanização e quimificação das lavouras; no trabalho precário e escravo; na violência e expulsão de famílias do campo; associando à monocultura, o aumento do uso de agrotóxicos e a introdução de cultivos transgênicos. O modelo de agricultura capitalista do agronegócio se afirma, então, como o principal responsável pela crise alimentar mundial, pois, ao tratar a terra, as sementes e os alimentos produzidos como mercadorias vem comprometendo a segurança alimentar, que além de não ter sido alcançada com a revolução verde, foi ainda agravada.

As mudanças operadas no padrão do desenvolvimento tecnológico produtivo da agricultura, não alteraram o padrão da estrutura agrária vigente, conservando e agravando o nível de desigualdade na distribuição da posse e uso da terra. As consequências sociais e ambientais deste modelo perverso de agricultura, reconhecidas em nível mundial, sustentam e justificam a idéia de construir uma agricultura alternativa a este modelo através da agroecologia.

Sevilla Gusmán (2006) nos ensina que a agroecologia tem como eixo estruturante as seguintes premissas: o homem é parte constitutiva e se relaciona histórica e socialmente com a natureza, junto com outras espécies animais, vegetais e os recursos naturais; o contexto sócio-cultural e humano tem presença marcante na agroecologia; a dimensão técnica e ambiental se consolida a partir do diálogo, da experimentação, da confrontaçãocomplementação entre o saber/cultura campesina e o saber técnico-científico; a dimensão política implica na defesa da biodiversidade, do ponto de vista critico, que se confronte com o capitalismo, força hegemônica no modelo de agricultura convencional.

A agroecologia tem como objetivo, para além da identificação e difusão de técnicas alternativas para a agricultura, pautar a questão da sustentabilidade da agricultura e do meio rural e suas implicações para a sociedade. Assim, este debate coloca em questão a relação sociedade-natureza, no sentido de criar uma nova conscientização social, estando aí implicada a criação de novas formas políticas e ideológicas. A agroecologia ao ultrapassar o enfoque das necessárias mudanças no padrão técnico da agricultura amplia-se para as indispensáveis transformações políticas em toda sociedade. 
Estas questões apontam os desafios políticos que se abrem aos movimentos sociais do campo, particularmente ao MST, e as possibilidades de convergências com outros sujeitos coletivos, como os movimentos ambientalistas, e especialmente com aqueles que se articulam em torno da defesa da produção de uma agricultura contraposta ao modelo capitalista de agricultura hegemônico.

\section{Questão ambiental, reforma agrária e agroecologia: desafios políticos ao MST}

O MST, criado em 1984, tem a sua trajetória marcada por três objetivos: a terra, a reforma agrária e a transformação da sociedade, que foram buscados inicialmente através da ocupação da terra, que parte de um movimento de resistência e defesa dos interesses dos trabalhadores. E a estratégia de ocupações teve que ser afirmada e defendida, como instrumento legítimo para a conquista dos objetivos postos pelo movimento.

Entre as lutas mais amplas ou mais restritas levadas adiante pelo MST, interessa-nos, particularmente, conhecer o processo de politização do que definimos como "questão ambiental", o qual acontece a partir de ações coletivas e mudanças políticas e institucionais, tendo como norte uma perspectiva que vise transformações societárias. Esse enfrentamento deve desvelar, entre outras dimensões, as desigualdades de poder sobre os recursos naturais e os conflitos, as tensões e os embates entre as classes sociais que se constituem pela participação desigual na estrutura produtiva e na desigualdade na distribuição e apropriação dos bens socialmente produzidos a partir das relações entre sociedade e natureza. Pretendemos analisar as potencialidades e desafios do MST, na busca de articulação em torno da questão ambiental como um eixo estratégico da luta contra o capital, tendo em conta a adoção da agroecologia como estratégia produtiva e política e a reforma agrária popular do MST.

No decorrer dos anos de 1984 a 1989, o MST iniciou seu processo de territorialização pelo Brasil, intensificando o processo de formação do campesinato. Desta forma, o impacto político causado pelas ocupações de terra transformou os sem-terra nos principais interlocutores no enfrentamento com o Estado, na luta pela terra e pela reforma agrária, na crítica ao modelo agrícola convencional e na defesa da segurança alimentar (Fernandes, 2000). 
A expansão do MST requereu mudanças na sua organização interna, que se deu de forma histórica, tendo sido criados setores, frentes, comissões, coletivos, dentre outros, a fim de suprir demandas postas. Nesta direção, houve o fortalecimento da organicidade do setor de produção, cooperação e meio ambiente que se fundamenta no princípio de

(...) não separar nas lutas pela terra e pela reforma agrária a dimensão econômica da dimensão política. Neste sentido se estabelece a necessária relação entre a organização simultânea da cooperação agrícola e das ocupações; o investimento na formação dos sem terra, tendo em vista as transformações da estrutura produtiva (MORISSAWA, 2001, p. 206).

A resolução de que o meio ambiente deveria ser um tema transversal na organização deste Movimento, vem fortalecer a busca de novas referências para os assentamentos, no sentido de como desenvolvê-los, numa perspectiva ampla, com preocupação com as questões sociais, econômicas e ambientais tendo como centralidade o acúmulo de forças. Nesta perspectiva, tornou-se necessário pensar o meio ambiente, de forma articulada ao processo de produção e de cooperação agrícola.

O assentamento é o renascimento da vida humana e da natureza' e por esta razão o MST tem estimulado a prática agroecológica, desenvolvendo uma nova forma de produzir que não prejudique o ser humano nem a natureza. Desde o ano de 1998 que a CONCRAB tem implementado diversas atividades relacionadas com o meio ambiente, com a promoção de uma ampla discussão nos assentamentos sobre como preservar os recursos naturais, o estímulo a campanhas de plantio de árvores e reflorestamento, a realização de estudos para sistematizar experiências de preservação do meio ambiente para servir de intercâmbio entre os assentados e difusão na sociedade, seminários de integração com outras entidades a fim de aproximar as teses ambientalistas com as da reforma agrária.[...]O MST inovou na produção das primeiras sementes orgânicas de hortaliças no país [...] produzidas pela primeira vez sem a utilização de nenhum tipo de agrotóxico ou insumo químico [...] O MST tem atuado na defesa da natureza não apenas implementando a agroecologia, mas também realizando mobilizações nos âmbitos nacional e internacional, contra o uso de métodos agrícolas que coloquem em risco a vida do planeta (MST, 2003, p. 10)

A análise dos documentos elaborados nos congressos nacionais do MST demonstra as mudanças ocorridas no processo de construção de sua proposta de reforma agrária e como a questão do meio ambiente passa a ser tratada e fortalecida. As cartas destes congressos e os lemas adotados para o direcionamento das linhas políticas de atuação sinalizam seu processo de amadurecimento e fortalecimento, abrangendo estratégias de resistência e ofensiva.

Os dois primeiros congressos nacionais do MST são realizados no contexto de seu processo de territorialização tendo clara a necessidade de organização interna para a afirmação da estratégia de ocupação de terras, como um instrumento legítimo de luta e para o 
desenvolvimento da produção coletiva dos assentamentos conquistados. Cabe destacar que a defesa da luta pela terra com as ocupações e a resistência na terra dos assentamentos impôs grandes desafios ao movimento, principalmente no que se refere à produção da agricultura camponesa em áreas com diversos problemas ambientais, como a degradação e contaminação dos solos e dos recursos hídricos. Tornou-se necessário fortalecer sua autonomia política e financeira e elaborar uma proposta política e organizativa para o setor de produção. Diante destes desafios o MST adota a estratégia de aproximação do campo com a cidade visando à urbanização da reforma agrária. O lema adotado no I Congresso Nacional (1985) "Sem reforma agrária não há democracia: Ocupação é a única solução" e no II Congresso (1990), "Ocupar, resistir, produzir", expressam esta conjuntura do movimento.

É importante dizer que mesmo com o esforço envidado pelo MST para a organização da produção da agricultura através da cooperação, não foi possível deixar de reproduzir o modelo de agricultura capitalista, considerando inclusive o atrelamento do repasse de crédito à adoção do pacote tecnológico hegemônico. No entanto, a criação das Cooperativas de Produção Agrícola - CPAs, e da Confederação de Cooperativas de Reforma Agrária do Brasil - CONCRAB foram significativas para o processo de desenvolvimento econômico e social, e para o fortalecimento do modelo de cooperação que contempla as primeiras experiências de produção alternativa.

Ao adotar o lema "Reforma Agrária: uma Luta de Todos", no III Congresso (1995) o MST buscou desenvolver a estratégia de aproximação campo e cidade trazendo para a toda a sociedade o debate em torno da importância e necessidade da reforma agrária, realizando neste período, ocupações em Brasília e duas grandes marchas nacionais, em 1997 e 1999. Em relação à proposição da reforma agrária e sua relação com a questão ambiental neste congresso, o MST já sinaliza a mudança necessária da produção abrangendo a adoção de tecnologias adequadas ao processo de recuperação e preservação dos recursos naturais para a garantia da segurança alimentar.

Consideramos relevante destacar que a partir do IV Congresso (2000) a agroecologia passa a ser assumida como um processo de construção de outro modelo produtivo em clara oposição ao modelo das classes dominantes que impõem os transgênicos, sob o comando das empresas transnacionais do agronegócio. A luta pela eliminação do latifúndio e da violência no campo se traduz no lema: "Reforma Agrária: por um Brasil sem Latifúndio" e expressa uma resposta do movimento aos dois grandes massacres de trabalhadores rurais ocorridos em Corumbiara (RO), em 1995, e em Eldorado dos Carajás (PA), em 1996. 
Este congresso reafirmou a importância do debate em torno de questões importantes como: meio ambiente, biodiversidade, água doce, defesa da bacia de São Francisco e da Amazônia. Em seu documento final, realizou a denúncia das linhas políticas do governo adotadas para a agricultura e propôs a realização de ações concretas para a construção de um novo modelo tecnológico, sustentável do ponto de vista ambiental, com garanta de produtividade, viabilidade econômica e bem-estar social.

O V Congresso Nacional (2007), com o lema "Reforma Agrária: por Justiça Social e Soberania Popular", representou uma tomada de deliberações em torno da defesa de uma proposta de reforma agrária de novo tipo, onde o discurso ambiental passa a se destacar como parte da reforma agrária e como luta para toda a sociedade. A defesa do planeta contra as inúmeras formas de agressão do capital passa a se constituir numa questão de sobrevivência da humanidade, o que exige e desafia a participação de toda sociedade. Nesta direção, o V Congresso tirou como linha política prioritária do MST, o fortalecimento das alianças, considerando que a adoção da bandeira ambiental requer o estabelecimento de diálogo com outros setores da sociedade, passando a ser um dos pilares do trabalho de base do MST.

O VI Congresso Nacional do MST(2014) adotou como lema: "Lutar, Construir Reforma Agrária Popular”. Dentre os objetivos estabelecidos, destacamos: eliminar a pobreza no campo; combater a desigualdade social, a exploração dos camponeses e a degradação da natureza; garantir a soberania; alimentar de toda população brasileira; preservar a biodiversidade vegetal, animal e cultural de cada região do Brasil, responsável por nossos diferentes biomas; garantir melhores condições de vida através de trabalho, renda, educação, moradia e lazer; defesa da participação igualitária das mulheres e de melhores oportunidades e condições para a permanência no campo, principalmente da juventude.

As mudanças necessárias são apresentadas através de medidas consideradas fundamentais e complementares reunidas em torno de pontos, sendo alguns mais diretamente relacionados à questão ambiental, onde destacamos a defesa não apenas da terra que precisa ser democratizada, mas também da água como bens dos povos e que deve estar a serviço de toda a humanidade; a organização da produção agrícola voltada para o cultivo de alimentos saudáveis e diversificada, como garantia do princípio da soberania alimentar através da agroecologia, gerando uma nova base alimentar.

O novo modelo tecnológico assumido afirma como uma das medidas necessárias, a massificação da agroecologia através da formação, da prática e da troca de experiências, da produção, distribuição e controle das sementes, da criação de um organismo público de 
certificação dos alimentos agroecológicos. Também se reafirma a necessidade de ruptura com a propriedade intelectual de patentes de variedades, sementes, recursos naturais ou sistemas de produção; a criação de máquinas e equipamentos agrícolas adaptados à produção camponesa e a realização de um programa nacional de reflorestamento tanto nos assentamentos quanto em áreas degradadas pelo agronegócio.

A reforma agrária popular do MST afirma ainda a necessidade de uma nova ação do Estado, e agrega demandas que ultrapassam a luta pelo acesso à terra e pela eliminação do latifúndio, como o acesso à saúde e à educação. O MST defende que a reforma agrária proposta tem como base a democratização da terra, mas a produção agroecológica busca produzir alimentos saudáveis para toda a população brasileira, o que de certo, não é possível para o modelo do agronegócio.

Para o MST (2013, p. 6), a implantação da reforma agrária popular está condicionada ao avanço das seguintes questões: capacidade de pressão sobre os governos obtendo conquistas (fator importante na luta de classes e na formação da consciência política da militância, porém insuficiente);correlação de forças no enfrentamento ao agronegócio;fortalecimento interno da organização do movimento;construção nos assentamentos e em outros espaços conquistados, do novo modelo de agricultura;construção e fortalecimento de alianças com a classe trabalhadora do campo e da cidade;construção de consensos em torno da compreensão e defesa de outro modelo de agricultura e democratização do Estado.

A efetividade da proposta de reforma agrária do MST requer a superação de uma diversidade de desafios, entre os quais destacamos: elevar o nível de consciência social, política e cultural de sua base social, e dos camponeses em geral; transformar os assentamentos desenvolvendo a agroecologia como estratégia de produção agrícola garantindo a soberania alimentar, respeitando o meio ambiente e a produção de alimentos sadios, combinada com áreas reflorestadas, com defesa da água e da biodiversidade (MST, 2007).

Mauro (2014, p.4) destaca que a nova leitura do movimento para a reforma agrária no contexto atual, precisa contemplar um amplo debate na sociedade brasileira em torno das seguintes questões: "que uso a humanidade, particularmente os brasileiros, quer dar à terra, à água, à biodiversidade, aos recursos naturais em geral?. Que tipo de comida queremos consumir? E que paradigmas tecnológicos de produção usaremos no próximo período?” 
Neste sentido, a disputa de consensos em torno da opinião pública sobre estas questões se coloca como central, uma vez que o uso atual destes recursos e a produção da agricultura, sob a hegemonia do capital, reforçam a idéia de que a reforma agrária se tornou desnecessária. A necessidade e atualidade da reforma agrária passa pela construção de consensos em torno da idéia de outro uso aos recursos naturais, com a produção de outro tipo de alimentação com menos impacto ao meio ambiente, e, principalmente, colocando os trabalhadores da terra no centro deste processo.

\title{
Considerações Finais
}

Leblon (2014) analisa a relevância do MST, ressaltando como sua atuação se faz necessária na intervenção da relação entre reforma agrária e questão ambiental. Concluímos, com o autor, que a chave do novo horizonte agrário certamente passa pelo tema ambiental, e que este é um grande desafio produtivo e político do MST.

\begin{abstract}
As imbricações entre a questão agrária e a urgência climática padecem, ademais, de uma quase uniforme negligência no debate programático da frente progressista que apoia o governo.[...]são agendas gêmeas indecifráveis de fato, enquanto mantidas dissociadas ou apenas vinculadas de forma ornamental nas prioridades de Estado.Uma, remanescente do século 19; a outra, contemporânea da exacerbação capitalista em nossos dias.Juntas, ao lado de outras, aguardam o desassombro de um protagonista político, capaz de arrastar tempos históricos distintos, dando-lhes a coerência impensável fora de uma agenda transformadora"."Não é pouco, como se vê, o que desafia o MST a se reinventar. Mas é isso que o faz necessário.E, indispensável, se for capaz de sacudir e romper as trancas que isolam o mundo rural - e a natureza - do debate sobre o novo ciclo de desenvolvimento do país (LEBLON, 2014,p.3).
\end{abstract}

O MST ao assumir a agroecologia, como estratégia produtiva e política, reúne elementos que potencializam sua proposta de reforma agrária popular, na disputa por outro modelo de produção da agricultura, contribuindo para o processo mais amplo de politização da questão agrária e ambiental na sociedade brasileira. A crítica ao atual modelo agrário e agrícola dominante requer a sustentação da agroecologia, em contraposição ao modelo do agronegócio que vem minando as duas fontes de produção de riquezas que são a natureza e o trabalho, gerando violência, superexploração do trabalho e devastação ambiental. 


\section{Referências Bibliográficas}

DELGADO, Guilherme Costa. A questão agrária e o agronegócio no Brasil. In: CARTER, Miguel (Org.). Combatendo a desigualdade social: o MST e a reforma agrária no Brasil. São Paulo: Ed. UNESP, 2010. p.81-112.

FERNANDES, B. Formação do MST no Brasil. Petrópolis: Vozes, 2000.

LEBLON, Saul. MST: o que o faz necessário. Carta Maior - Editorial, São Paulo, 14 fev. 2014. Disponível em: 〈http://www.cartamaior.com.br>. Acesso em: 17 fev. 2014.

MAURO, Gilmar. Luta do MST de hoje é contra o modelo do capital na agricultura e necessita de toda a sociedade. Entrevistado por Gabriel Brito e Valéria Nader. Correio da Cidadania, São Paulo, edição 896, 10 fev. 2014. Disponível em: <www.correiocidadania.com.br〉. Acesso em: 20 fev. 2014.

MENDONÇA, Sônia Regina. A questão agrária no Brasil: a classe dominante agrária natureza e comportamento 1964-1990. Coleção A questão agrária no Brasil, n5. João Pedro Stédile (org). São Paulo: Expressão Popular, 2006.

MORISSAWA, Mitsue. A história da luta pela terra e o MST. São Paulo: Expressão Popular, 2001.

MOTTA, Márcia (org). Dicionário da Terra. Rio de Janeiro: Civilização Brasileira, 2005.

MST. Documento elaborado para o Encontro das Agências de Desenvolvimento. Porto Alegre, 2003.

Proposta de Reforma Agrária Popular do MST. In: STÉDILE, João Pedro (org), Douglas Estevam (assistente de pesquisa). A questão agrária no Brasil: debate sobre a situação e perspectivas da reforma agrária na década de 2000. São Paulo: Expressão Popular, 2013.

SEVILLA GUSMÀn, Eduardo Sobre la articulacion de la Agronomia y la Ecologia en el Pensamiento Social Agrario. São Paulo: Seminário Interno do MST, 2006. 